\title{
PREFACE TO THE 2003 EDITION
}

HE FIRST EDITION of Caring was published in 1984. In the inter-
vening years, thanks to constructive criticism from people in a
variety of fields, I have learned a great deal about my own project. I know more clearly what I was trying to do, what I should have explained more fully, and what I should not have said at all. If I were to undertake the project now, Caring would be a different book, but the text of this edition has not been changed. In this brief preface, I will point to some of the issues that new readers should consider.

Perhaps the greatest contribution of care theory as it is developed here is its emphasis on the caring relation. Relations, not individuals, are ontologically basic, and I use "caring" to describe a certain kind of relation or encounter. It is certainly true that "caring" is also construed as a virtue, as an attribute or disposition frequently exercised by a moral agent. I used the term both ways in Caring, and I was not always careful in noting the distinction. However, my intention is clearly stated at the end of chapter 2 (on the one-caring): "But caring is a relationship that contains another, the cared-for, and we have already suggested that the one-caring and the cared-for are reciprocally dependent" (p. 58). Both play significant parts in caring relations.

The reciprocity in caring relations is not contractual; that is, we do not expect the cared-for to balance the relation by doing what the one-caring (or carer) does. In equal relations, we do expect that, under appropriate conditions, the parties will exchange places as carer and cared-for. The world is not divided into carers and cared-fors as separate and permanent classes. We are all inevitably cared-fors at many times and, ideally, most of us are carers.

However, many relations are not equal or symmetric, and it is in analyzing unequal relations that we see the special contribution of the cared-for. By recognizing the carer's efforts, by responding in some positive way, the cared-for makes a distinctive contribution to the relation and establishes it as caring. In this way, infants contribute to the parent-child rela- 
tion, patients to the physician-patient relation, and students to the teacherstudent relation.

Traditional moral philosophy has overlooked the contributions of the cared-for because these contributions cannot always be described in terms of moral agency or adherence to principle. Indeed, some philosophers object to my emphasis on the contribution of the cared-for, as cared-for, because it seems to give moral credit to the infant's wriggles and smiles, the patient's sigh of relief, and student's eager pursuit of her own projects. But the ethic of care is not about moral credit. It is about moral life and what makes it possible. The contributions of the cared-for sustain us in our attempts to care.

There is great practical power in moving beyond credit, blame, and a narrow focus on justification. Consider a situation familiar to educators. Students in a given high school say that they want their teachers to care for them, but "nobody cares." Their teachers make a convincing case that they do care (in the virtue sense); they work hard and want their students to succeed. Here we have willing carers and willing cared-fors but no caring relations. The teachers may or may not be at fault, and the same can be said of the students. Both may be blameless, and the fault may lie in the situation-in the structures and routines of their school. Through a relational perspective, we are encouraged to study the conditions that make it possible for caring relations to flourish. This way of thinking can be generally useful in the construction of social policy. (See my Starting at Home: Caring and Social Policy, 2002.)

Today, in a world shaken by the violence of nations and groups whose acts are "justified" by the principles they espouse, an ethic of care is even more important and ultimately reasonable. Our efforts should be directed to transforming the conditions that make caring difficult or impossible. This means working to eliminate poverty and exploitation, protecting the earth as the home of all living things, and rejecting violence as a means of defense except under conditions of direct attack and then only to prevent immediate harm. A primary message of Caring is that we cannot justify ourselves as carers by claiming "we care." If the recipients of our care insist that "nobody cares," caring relations do not exist.

We often justify our acts, especially those that cause harm, by claiming adherence to a recognized moral principle. I have suggested that principles and rules are not as central to moral life as many traditional philosophers have supposed. It is not that principles and justification are unimportant; I hope to give more attention to them in a future work. But 
available empirical evidence suggests that individuals only rarely consult moral principles when making decisions that result in the prevention of harm. More often, people respond directly as carers (out of sympathy) or as faithful members of a community that espouses helping and not harming. In considering education, then, we have to ask how best to cultivate the moral sentiments and how to develop communities that will support, not destroy, caring relations.

Critics have sometimes objected to my view of principles by saying that the ethic of care itself stands on a principle: always act so as to establish, maintain, or enhance caring relations. But this claim is a confusion in types of principle. The principle as stated is a good descriptive principle; it tells us what an observer sees in watching caring relations. But carers do not normally consult this principle before acting; it is not a dependable prescriptive principle. People who care usually do so naturally and directly because they want to respond positively to those addressing them.

There are times, of course, when we do not feel like caring, and then I've said we have to draw on our "ethical ideal"-our history of caring and the high value we place on ourselves as carers. In this approach, care theorists are close to virtue ethicists who depend heavily on the character of moral agents. Our priority, however, is on natural caring, and our efforts at ethical caring are meant to establish or re-establish the more dependable conditions under which caring relations thrive. Ethical caring, as necessary as it is, is always risky because the ethical agent's attention is diverted from the cared-for to his or her own ethical self (or even to the principle that I've claimed is rarely used prescriptively). If the cared-for sees this and calls us on it-"you don't really care"-relations are likely to become even more difficult.

One of the strongest criticisms of Caring was induced by my attempt to distinguish between caring-for and caring-about. The complaint is that caring (as I described it) is parochial; that is, it concentrates too narrowly on home and small community. Caring-for is the direct face-to-face attempt to respond to the needs of a cared-for. It uses the response of the cared-for in monitoring and shaping what it does to meet these needs, and my purpose in Caring was to analyze and describe caring-for in all its fullness. In contrast to caring-for, caring-about is characterized by some distance. It moves us from the face-to-face world of direct responsibility into the wider public realm. I contended (and I still believe) that we cannot care-for everyone, but there is a sense in which we can care-about a much wider population, and I did not give enough importance to caring- 
about. I have tried to rectify that in Starting at Home. There I have suggested that caring-about may be thought of as the motivational foundation for justice, and we need to use justice when it is logistically impossible to exercise caring-for. However, I stand by my claim that both caring-about and justice may miscarry if we do not follow up to see whether our efforts have produced conditions under which caring-for actually occurs. Caringfor is both the means by which most people come to care-about and the end that should be achieved by caring-about.

Attitudes change over a period of twenty years. When Caring first appeared, I endured a multitude of criticisms for my use of the word "feminine." Why not "feminist"? I am a feminist, certainly, and I believe that Caring fits into the theoretical category of relational feminism. But when I wrote Caring, I did not know much about feminist theory. I was working my own way through a set of problems, and I chose "feminine" to direct attention to centuries of experience more typical of women than men. "Feminine" pointed to a mode of experience, not to an essential characteristic of women, and I wanted to make clear that men might also share this experience. I still believe that, if we want males to participate fully in caring, a change of experience is required, starting in childhood. Abstract attempts at re-education probably will not work.

The formal responses and correspondence evoked by Caring have enriched my later work and enlarged my circle of colleagues. It has been gratifying to see Caring used (and criticized) not only in philosophy and education but also in law, nursing, medicine, social work, psychology, religion, feminist studies, peace studies, sociology, and even library science. For that enrichment of my own experience, I thank generous readers and writers.

Nel Noddings 